\title{
Factory Manufactured Modular Construction of Process Plants
}

\author{
Paul Wrigley a, Paul Wood a, Sam O’Neill ${ }^{\mathrm{b}}$, Richard Hall ${ }^{\mathrm{c}}$ and Daniel Robertson ${ }^{\mathrm{d}}$ \\ ${ }^{a}$ Institute for Innovation in Sustainable Engineering, University of Derby, UK \\ ${ }^{b}$ School of Electronics, Computing and Mathematics, University of Derby, UK \\ ${ }^{c}$ Nuclear AMRC, University of Sheffield, Rotherham S60 5WG, UK \\ ${ }^{d}$ Rolls-Royce Plc. Derby, UK
}

\begin{abstract}
Off-Site Modular Construction (OSMC) research has been a growing research area over the past two decades because of low productivity in construction. Tools are superior in factories and productivity is much higher compared to a stick built site. This has spawned the development small, factory built, rapidly deployable and flexible process plants to take advantage of the gains in OSMC productivity. Chemical process plant research is studying fast, automated design and configuration.

In this paper, a literature review was performed on modular factory manufactured process plants. The literature review found that moving to small scale OSMC plant systems could enable cost and schedule savings and months of design time compared to the previous on-site assembly design. It was also found that while automation has been applied in earlier stages of the plant design process, a layout optimisation methodology has not been applied to small OSMC process plants.

The paper then proposes to utilise a mathematical layout optimisation model to help design and construct modular process plants and considers how this may fit into the process plant design process, as well as considering the transport requirements for modules.
\end{abstract}

Keywords. Off-Site Modular Construction, prefabricated manufacture of industrial process plants,

\section{Introduction}

Low productivity in the construction industry (Figure 1) has seen the move to off site modular manufacting over the past few decades [1] [2], whereas there are suggestions that automation will be required for further productivity enhancements [3]. This off site modular manufacting has greatly increased the amount of research conducted on BIM [4].

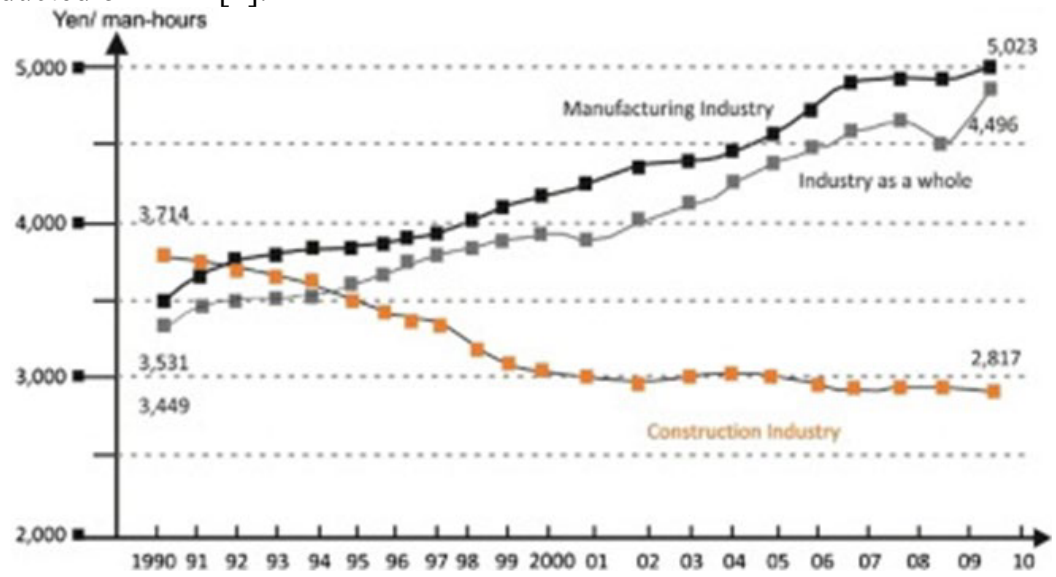

Figure 1. Labour productivity in industry and in the manufacturing industry is continuously rising; labour productivity in construction has been decreasing for decades [5] (C) Elsevier 
Modularisation of process plants has mainly focused on large modules in recent decades such as those in remote locations (Figure 2) with poor availability of labour and adverse weather conditions. Recent literature suggests up to a $20 \%$ capital cost saving and up to $50 \%$ schedule saving [6].

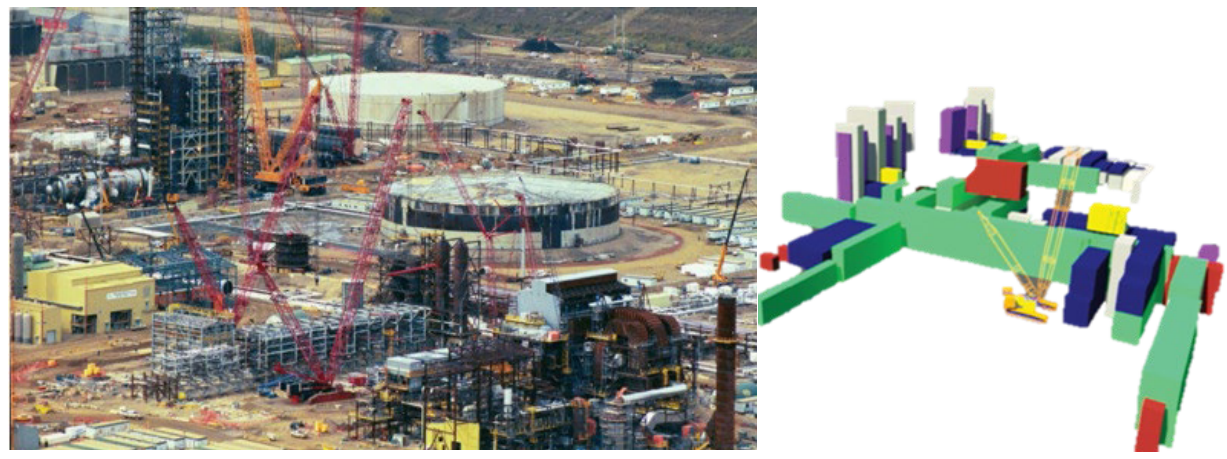

Figure 2 A modular industrial plant project in Alberta Canada [7] C Elsevier

A heuristic rule from experience in shipbuilding, recognised that work completed in a factory is $8 \mathrm{x}$ more cost and time efficient (Figure 3 ) than completing the same work on a construction site [8].

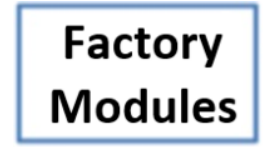

1x

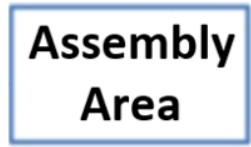

$3 x$

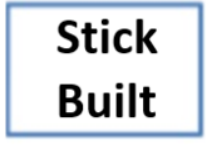

$8 x$

Figure 3. 1-3-8 rule from shipbuilding [8] @ Elsevier

However, small scale, modular factory manufactured process plants (Figure 4) has been a growing area of research over the past decade [9]. This is mainly due to the low productivity experienced in the construction industry shown in Figure 1.

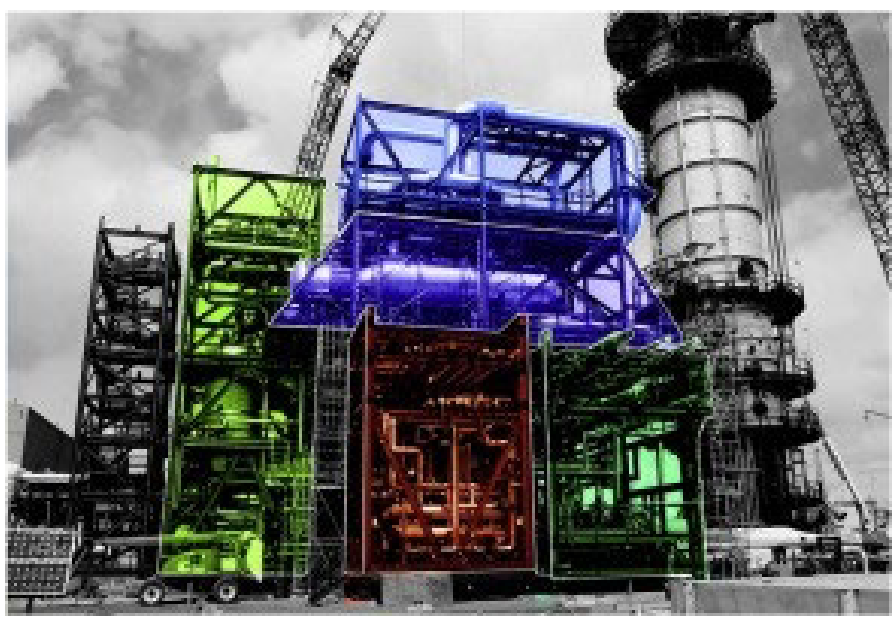

Figure 4. Modular factory manufactured process plants [9] (C) Elsevier 


\section{Literature}

Seifert et al., highlighted that small modular plants (example in Figure 5) can decrease the construction schedule by over 2 years (66\%) and improve value by $35 \%$. Changing to a continuous process rather than batch can achieve $30 \%$ better value [10].

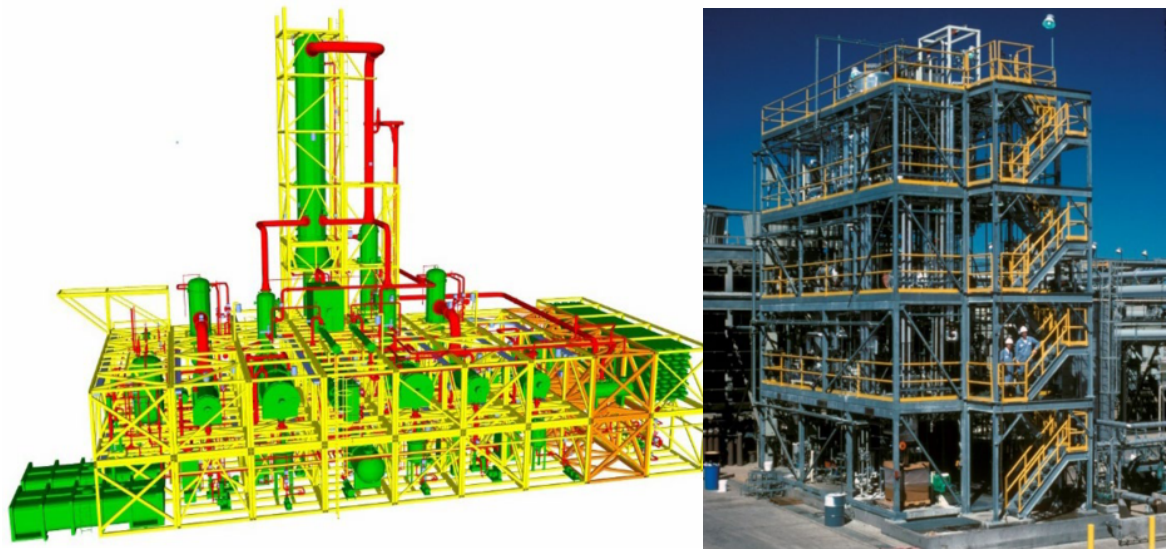

Figure 5 - Off site modular constructed process plants [11] (Photos Courtesy of Zeton [12])

Equipment module databases were first studied, supporting plant designers to rapidly pick equipment and equipment modules [11] [13] [14] [15]. Clustering approaches were suggested to design modules [16] as well as accumulating data from past projects [17]. A method to remove the need for an assembly factory was suggested where equipment is fit at the equipment manufacture, however more effort is necessary at site to join the module connections [18]. Selection techniques for equipment utilising reusable databases were then developed [19] and also for modules [20] [21] [22] [23] to speed up the design process. Modular Piping and Instrumentation Diagrams (P\&ID) were configured out of "basic and auxiliary elements" [24]. Support tools were established to determine applicability of modular expansions of existing plants [25] and expansion planning for new plants [26]. Up to $70 \%$ decreases on construction costs and $41 \%$ of engineering costs for modular plants were shown with a capital investment estimation tool [27].

\section{Method}

Whereas a lot of work has been done on modular equipment databases, process flow diagrams, and P\&IDs, very little work has been done on 3D layout for small, factorybuilt process plants [22]. A method to utilize layout optimisation to analyse concepts of off site modular factory manufactured process plants was proposed [28]. Automated design techniques were highlighted [29] and a method to arrange modules in a process plant developed [30]. Layout optimisation models have been applied for optimising construction, safety, operational costs [31] in the industrial process plant research.

Figure 6 shows the proposal for how a layout optimisation method for Factory manufactured modular process plants may fit in to the process plant design process. 


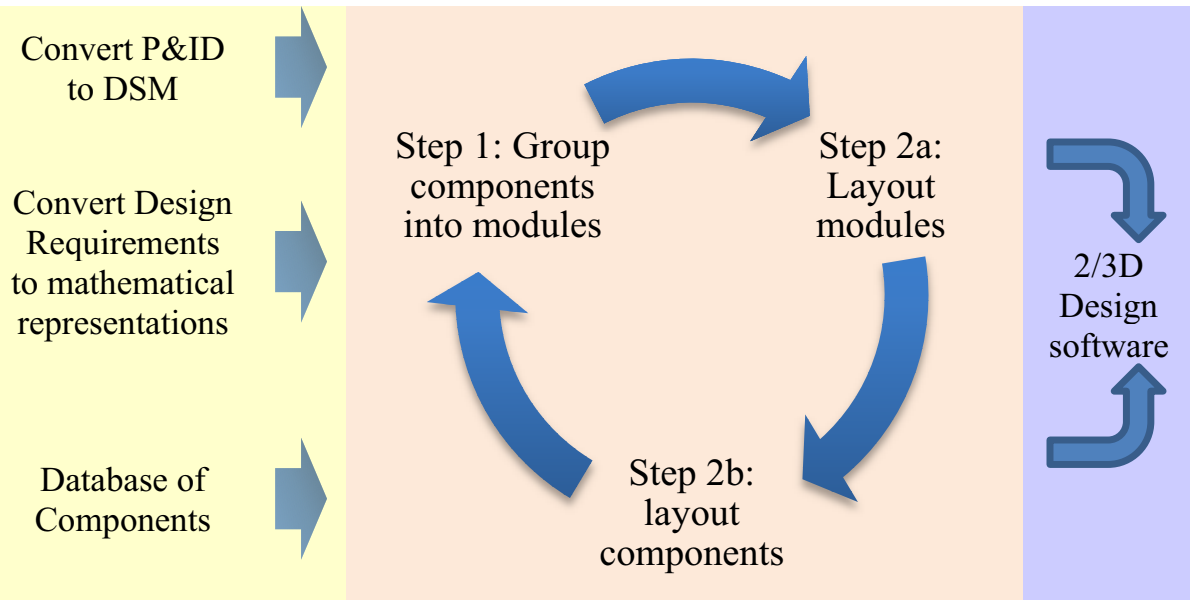

Figure 6. Factory manufactured modular process plants design process proposal

The design process needs to consider design for manufacture and transport such as factory build requirements Figure 7.

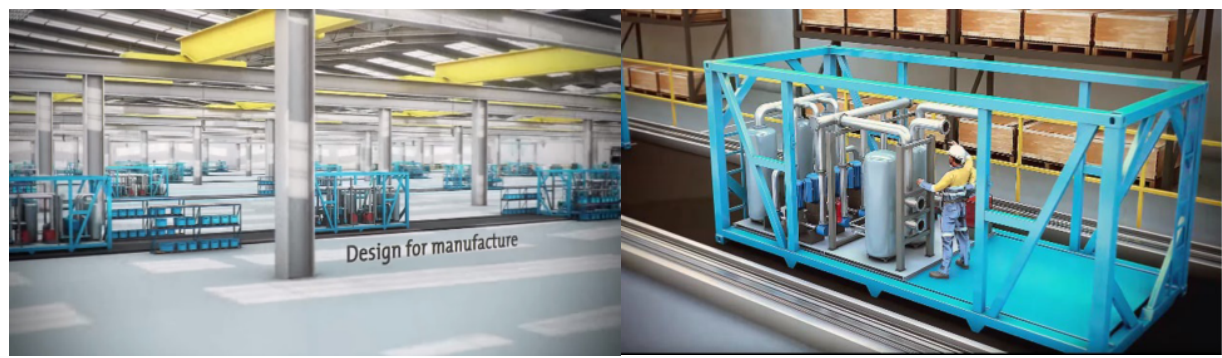

Figure 7 - Rolls-Royce concept for factory-built modules (C) Rolls-Royce Plc

The move to factory-built modules and transport (Figure 8) could become even more economical as the world moves towards a future of electric, driverless vehicles [28].

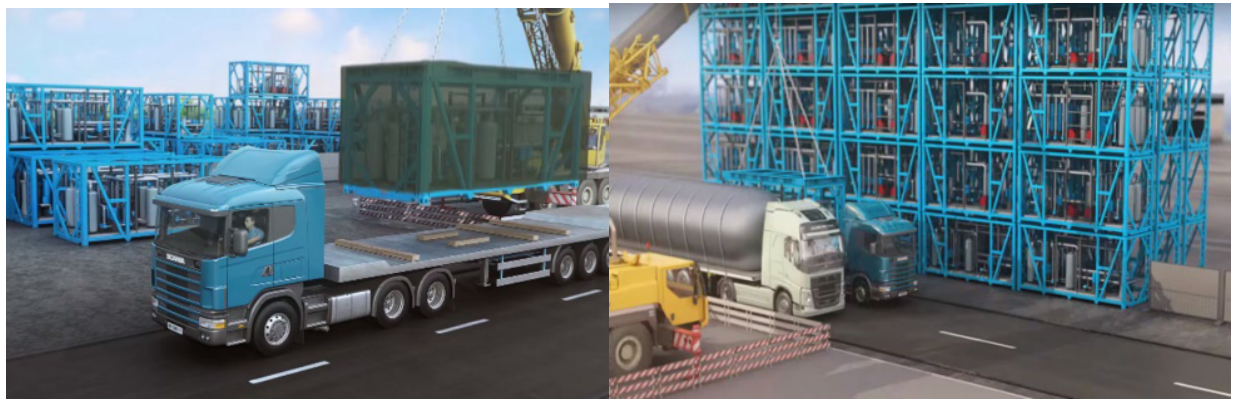

Figure 8 - Rolls-Royce concept for module transportation (C Rolls-Royce Plc 


\section{Road Transport Requirements}

Off-site construction in factory manufactured process plant modules improves productivity, quality and involves less rework, aiding the construction timetable.

So that work off site is increased, modules ought to be designed for upper limits of road transport. Site position is key for transport and is recommended to be chosen prior to more considerations being determined (insurance, special equipment, licences, quality control, possible incidents and obstructions, environment, etc) [32], [6]. In conjunction with Site position, module size and transportation constraints should be explored.

The UK and EU road transport restrictions are considered in Table 1.

Table 1 - Module dimensions for transport for UK police and Highways England (HE) notice [31]

\begin{tabular}{llllc}
\hline Transportation Requirement & $\begin{array}{l}\text { Weight } \\
\text { (tonnes) }\end{array}$ & $\begin{array}{l}\text { Width } \\
\text { (metres) }\end{array}$ & $\begin{array}{l}\text { Length } \\
\text { (metres) }\end{array}$ & $\begin{array}{l}\text { Height } \\
\text { (metres) }\end{array}$ \\
\hline STGO no permit & 80 & 3 & 18.75 & 4.95 \\
2 clear days' Police notice & 150 & 5.0 & & 4.95 \\
HE form VR1* & & 6.1 & & 4.95 \\
HE Special Order* & $>150$ & $>6.1$ & $>30.0$ & 4.95 \\
\hline
\end{tabular}

Within the EU no permit is needed for vehicle loads [33] of:

Width - 3m, Length - 24m, Height $-4 m$.

\section{Conclusions}

Factory manufactured process plants is a developing research area. This paper highlights previous research in small scale, off site manufactured and constructed industrial process plants. It recognises that although research into automation has been achieved in the earlier parts of the design process (PFD, P\&ID, equipment databases), there is little available research on a layout optimisation method for modular process plants.

The paper then proposes how a layout optimisation method may fit into the process plant design process and considers transport requirements for modules.

\section{Acknowledgements}

Funded by Rolls-Royce Plc for the UK SMR team and the University of Derby.

\section{References}

[1] M. R. Hosseini, I. Martek, E. K. Zavadskas, A. A. Aibinu, M. Arashpour, and N. Chileshe, "Critical evaluation of off-site construction research: A Scientometric analysis,” Autom. Constr., vol. 87, no. July 2017, pp. 235-247, 2018.

[2] R. Jin, S. Gao, A. Cheshmehzangi, and E. Aboagye-Nimo, "A holistic review of off-site construction literature published between 2008 and 2018," J. Clean. Prod., vol. 202, pp. 1202-1219, 2018.

[3] T. Bock, "The future of construction automation: Technological disruption and the upcoming ubiquity of robotics," Autom. Constr., vol. 59, pp. 113-121, 2015.

[4] X. Yin, H. Liu, Y. Chen, and M. Al-Hussein, "Building information modelling for off-site construction: Review and future directions," Autom. Constr., vol. 101, no. October 2018, pp. 72-91, 2019.

[5] T. Bock, "The future of construction automation: Technological disruption and the upcoming ubiquity of robotics," Autom. Constr., vol. 59, pp. 113-121, 2015.

[6] B. Mignacca and G. Locatelli, "Economics and finance of Small Modular Reactors: A systematic review and research agenda," Renew. Sustain. Energy Rev., vol. 118, no. September 2019, p. 109519, 2020.

[7] H. Taghaddos, U. Hermann, and A. B. Abbasi, "Automated Crane Planning and Optimization for modular construction," Autom. Constr., vol. 95, no. July, pp. 219-232, 2018. 
[8] K. Barry, "Modularization of Equipment for New Nuclear Applications," 2009.

[9] J. Bielenberg and I. Palou-Rivera, "The RAPID Manufacturing Institute - Reenergizing US efforts in process intensification and modular chemical processing," Chem. Eng. Process. - Process Intensif., vol. 138, no. February, pp. 49-54, 2019.

[10] T. Seifert, S. Sievers, C. Bramsiepe, and G. Schembecker, "Small scale, modular and continuous: A new approach in plant design," Chem. Eng. Process. Process Intensif., vol. 52, pp. 140-150, 2012.

[11] C. Bramsiepe et al., "Low-cost small scale processing technologies for production applications in various environments-Mass produced factories," Chem. Eng. Process. Process Intensif., vol. 51, pp. 32 $52,2012$.

[12] Zeton, "Modular Fabrication," 2019. [Online]. Available: http://www.zeton.com/site/modularfabrication.html.

[13] N. Kockmann, "Modular Equipment for Chemical Process Development and Small-Scale Production in Multipurpose Plants," ChemBioEng Rev., vol. 3, no. 1, pp. 5-15, Feb. 2016.

[14] M. Eilermann, C. Post, D. Schwarz, S. Leufke, G. Schembecker, and C. Bramsiepe, "Generation of an equipment module database for heat exchangers by cluster analysis of industrial applications," Chem. Eng. Sci., vol. 167, pp. 278-287, 2017.

[15] M. Eilermann, C. Schach, P. Sander, C. Bramsiepe, and G. Schembecker, "Generation of an equipment module database - A maximum coverage problem," Chem. Eng. Res. Des., vol. 148, pp. 164-168, 2019.

[16] H. Radatz, J. M. Elischewski, M. Heitmann, G. Schembecker, and C. Bramsiepe, "Design of equipment modules for flexibility," 2017.

[17] C. Fleischer-Trebes, N. Krasberg, C. Bramsiepe, and N. Kockmann, "Planning Approach for Modular Plants in the Chemical Industry," Chemie Ing. Tech., vol. 89, no. 6, pp. 785-799, Jun. 2017.

[18] A. C. Kadak and M. V. Berte, "Advanced modularity design for the MIT pebble bed reactor," in Nuclear Engineering and Design, 2006, vol. 236, no. 5-6, pp. 502-509.

[19] N. Krasberg, L. Hohmann, T. Bieringer, C. Bramsiepe, and N. Kockmann, "Selection of Technical Reactor Equipment for Modular, Continuous Small-Scale Plants," Processes, vol. 2, no. 1, pp. 265-292, 2014.

[20] Ł. Hady and G. Wozny, "Computer-aided web-based application to modular plant design," Computer Aided Chemical Engineering, vol. 28, no. C. pp. 685-690, 2010.

[21] L. Hohmann, K. Kössl, N. Kockmann, G. Schembecker, and C. Bramsiepe, "Modules in process industry - A life cycle definition," Chem. Eng. Process. Process Intensif., vol. 111, pp. 115-126, 2017.

[22] M. Eilermann, C. Post, H. Radatz, C. Bramsiepe, and G. Schembecker, "A general approach to modulebased plant design," Chem. Eng. Res. Des., vol. 137, pp. 125-140, 2018.

[23] H. Radatz, M. Schröder, C. Becker, C. Bramsiepe, and G. Schembecker, "Selection of equipment modules for a flexible modular production plant by a multi-objective evolutionary algorithm," Comput. Chem. Eng., vol. 123, pp. 196-221, 2019.

[24] Uzuner, "Ein Beitrag zur wissensbasierten Unterstützung bei der Auswahl technischer Ressourcen," Hamburg, 2017.

[25] T. Seifert, H. Schreider, S. Sievers, G. Schembecker, and C. Bramsiepe, "Real option framework for equipment wise expansion of modular plants applied to the design of a continuous multiproduct plant," Chem. Eng. Res. Des., vol. 93, pp. 511-521, 2015.

[26] S. Sievers, T. Seifert, G. Schembecker, and C. Bramsiepe, "Methodology for evaluating modular production concepts," Chem. Eng. Sci., vol. 155, pp. 153-166, 2016.

[27] S. Sievers, T. Seifert, M. Franzen, G. Schembecker, and C. Bramsiepe, "Fixed capital investment estimation for modular production plants," Chem. Eng. Sci., 2016.

[28] P. Wrigley, P. Stewart, R. Hall, P. Wood, and D. Robertson, "Design for plant modularisation: Nuclear and SMR," in International Conference on Nuclear Engineering, Proceedings, ICONE, 2018, vol. 9, p. V009T16A051.

[29] P. Wrigley, P. Wood, P. Stewart, D. Robertson, R. Hall, and K. Ellis, "Automated design techniques for new nuclear power plant design: Knowledge based engineering, generative design and optimisation," in 27th International Conference on Nuclear Engineering, 2019.

[30] P. A. Wrigley, P. Wood, P. Stewart, R. Hall, and D. Robertson, "Module layout optimization using a genetic algorithm in light water modular nuclear reactor power plants," Nucl. Eng. Des., vol. 341, pp. $100-111,2019$.

[31] J. O. Ejeh, S. Liu, and L. G. Papageorgiou, "Optimal layout of multi-floor process plants using MILP," Comput. Chem. Eng., vol. 131, p. 106573, 2019.

[32] B. Mignacca, A. H. Alawneh, and G. Locatelli, "Transportation of small modular reactor modules: What do the experts say?," in International Conference on Nuclear Engineering, Proceedings, ICONE, 2019.

[33] J. Barrot, European Best Practice Guidelines for Abnormal Road Transports. EU, 2019. 